First Peoples Child \& Family Review

An Interdisciplinary Journal Honouring the Voices, Perspectives, and Knowledges of First Peoples through Research, Critical Analyses, Stories, Standpoints and Media Reviews

\title{
Indigenous Knowledge, Community and Education in a Western System: An Integrative Approach
}

\section{Danika Overmars}

\section{Volume 5, Number 2, 2010}

URI: https://id.erudit.org/iderudit/1068934ar

DOI: https://doi.org/10.7202/1068934ar

See table of contents

Publisher(s)

First Nations Child and Family Caring Society of Canada

ISSN

1708-489X (print)

2293-6610 (digital)

Explore this journal

Cite this article

Overmars, D. (2010). Indigenous Knowledge, Community and Education in a Western System: An Integrative Approach. First Peoples Child \& Family Review, 5(2), 88-95. https://doi.org/10.7202/1068934ar 


\title{
First Peoples Child \& Family Review
}

An Interdisciplinary Journal Honoring the Voices, Perspectives and Knowledges of First Peoples through Research, Critical Analyses, Stories, Standpoints and Media Reviews

\section{Volume 5, Number 2, 2010, pp. 88-95}

\section{Indigenous Knowledge, Community and Education in a Western System: An Integrative Approach}

\author{
Danika Overmars ${ }^{a}$
}

\begin{abstract}
Master of Arts Student at Ontario Institute for Studies in Education at the University of Toronto, Department of Adult Education and Counselling Psychology.
\end{abstract}

\section{Introduction}

Epictetus once said "only the educated are free." When applied to Indigenous people in Canada, it is seen that the government attempted to remove the freedom of Indigenous peoples by expunging Indigenous knowledge. Residential schools were designed to eradicate Indigenous knowledge and Indigenous ways of knowing under the guise of providing education to Aboriginal peoples in Canada (Schissel \& Wotherspoon, 2003). The residential school system forcefully removed children from their families and disconnected children from their culture. Residential school was one of the most destructive colonial practices and the impact of the intergenerational trauma caused by the residential school system continues to be evident in the educational system (Battiste, 1998). Only recently has the Canadian government issued an apology for the assimilation policies of residential school (O’Neil \& Dalrymple,2008). Robertson (2006) suggests that it may take many generations for Aboriginal peoples to heal from the impact of the residential school system.

Questions or correspondence concerning this article may be addressed to:

Danika Overmars

d.overmars@utoronto.ca

Phone: 647.213 .3686

Fax: 416.926 .4749

Room 7-230, 252 Bloor Street West,

Toronto, ON, M5S $1 \mathrm{~V} 6$

\begin{abstract}
Colonization attempted to eradicate Indigenous knowledge and Indigenous Ways of knowing through coerced education, yet education may be the key to the healing journey for Aboriginal people in Canada. At present the educational system is not serving Aboriginal students well as measured by levels of student success. The integration of Indigenous knowledge, community and education increases the likelihood of success of students in educational settings and promotes healing from colonization. Research suggests that a community based model of education is not only appropriate for Aboriginal students but is likely to enhance their education by providing community controlled and culturally relevant experiences.
\end{abstract}

Keywords: Indigenous knowledge, community-based education, policy.

The present educational system remains rife with challenges for Aboriginal students as reflected in the low rates of attendance and completion of high school (Milligan \& Bougie, 2009). It is also evident in the gaps in levels of attainment in postsecondary education (Milligan and Bougie).These challenges are arguably reflective of an educational system that has not yet learned to fully support Aboriginal students. This paper argues that supporting Aboriginal students and improving their experiences in the educational system is inextricably linked to restoring and honouring Indigenous knowledge and Indigenous ways of knowing. However, one cannot escape the Western ways of knowing entirely and it is suggested that the most beneficial approach would respect and integrate both Western and Indigenous ways of knowing. It is suggested that there are values in Indigenous cultures, such as interconnectedness, which lend to a community based approach to education for Aboriginal peoples. This paper outlines how community based education provides a strategy for integrating Indigenous knowledge into a Western based educational system. 


\section{Indigenous knowledge}

Indigenous ways of knowing are the pedagogies, or processes, of learning in Indigenous cultures (Pember, 2008). Indigenous knowledge is a reflection of Indigenous ways of knowing. Indigenous knowledge has been defined as the cosmologies, values, cultural beliefs, and webs of relationships which are embodied in specific communities (Dei, 2002). Indigenous knowledge is as diverse as the communities in which it based and Aboriginal populations in Canada and the United States have significant within-group differences in language, traditions, and cultural practices (Restoule, 1997; Warner, 2006). These differences are reflected in the Indigenous knowledge of the groups because Indigenous knowledge is rooted in language and culture (Pember, 2008; Steinhauer, 2002). Consequently, it would be erroneous to imply that there is a ubiquitous Indigenous knowledge that would apply equally to all groups of Aboriginal people (Brayboy \& Castagno, 2008); nonetheless, there are commonalities which are shared among Aboriginal peoples.

One such commonality is the theme of interconnectedness. Interconnectedness, or interdependence, was necessary for survival when Indigenous groups were engaged in subsistence activities (Roué, 2006). Interconnectedness incorporates the idea that all things in the natural world are related (Steinhauer, 2002); the impact of actions on all things - mineral, vegetation, animal and human - are considered with equal regard.. Aboriginal peoples have a great respect for the land and strive for a harmonious relationship with nature. This holistic framework lends to what is often termed a collectivist approach where the needs of the community supersede the needs of any individual (International Working Group for Indigenous Affairs, 1996). Collectivist social structures are often juxtaposed against individualistic structures wherein the individual's needs are placed above those of the community or social group. Individualistic approaches tend to dominate in mainstream Western culture and these attitudes are visible throughout the academic systems. For example, in classroom settings individual assignments predominate and individual grades are given; there are few, if any, attempts to create a sense of community where the needs of the group would supersede the needs of the individual student.

Holism is also a theme within an Indigenous framework. A prominent example of this is the Medicine wheel which originated with the Plains nations (Bopp \& Bopp, 2001; Dumbrill \& Green, 2007). The medicine wheel has four quadrants which can represent a number of different things based on the context in which the medicine wheel is placed. When the medicine wheel refers to an individual the quadrants represent the aspects of a human being: the spirit, the intellect, the emotions and the physical body; when applied to a community the four quadrants represent: the political and administrative aspects; the cultural and spiritual aspects; social aspects; and economic and environmental aspects. There is also a medicine wheel related to human and community development which includes the wider world: the person, family clan or group and the community itself and society. Indigenous ways of knowing suggest that the four components, in any medicine wheel, are intimately interrelated and that anything that affects one will impact the others by proxy (Bopp \& Bopp, 2001). For example, if an individual suffers from a physical wound he or she will also feel the repercussions mentally, emotionally and spiritually.

Indigenous knowledge is a fluid, living process rather than being a static construction based in the past (Steinhauer, 2002). Indigenous knowledge is deeply personal and as result does not claim to be 'the' truth (Castellano, 1999). Castellano suggests that the personal nature of Indigenous knowledge allows for discordant perspectives to be valid because they are unique to the individual.

Wane (2008) states that Indigenous knowledge is a living experience that is informed by ancestral voices. This can be taken both literally and figuratively, in that ancestral history is passed down through an oral tradition while in the figurative sense it is the knowledge or voices of the ancestors that are being heard in the present. Indigenous knowledge was traditionally passed down orally by Elders in the community (Castellano, 1999). Western scholars often depict this as primitive, by using terms such as preliterate, yet when it is carefully considered there are excellent reasons for disseminating information through oral traditions rather than through literary works. Castellano discusses a number of reasons for the reluctance of Elders to have their teachings recorded. It is suggested that recording or printing information adds a level of authority to the information and removes the ability for the information to be presented in the context of a relationship. Also, when Indigenous knowledge is passed on orally the Elder can adapt the content to reflect the maturity level of the recipient; once material is in print it lacks the ability to be personalized. Finally, the oral tradition is reflective of the fluid nature of Indigenous knowledge; oral stories are adaptable whereas print is fixed. As such, there are benefits to the oral tradition used by Indigenous peoples.

Castellano (1999) identifies three components that encompass Indigenous knowledge: traditional knowledge, empirical knowledge and revealed knowledge. Traditional knowledge is knowledge which has been passed down generationally. Traditional knowledge often includes the story of creation, ancestral rights to territories, clan origins in encounters with animals, and tales of battles. It is through this traditional knowledge that values are instilled and reinforced. Elders are 
often entrusted with this privilege and are given the primary responsibility for educating children through story (Pember, 2008).

There is a component of empirical knowledge in Indigenous knowledge, despite what Western science might suggest (Pember, 2008). Empirical knowledge consists of that knowledge which is gained by careful observations. An example of this is seen in Aboriginal knowledge of ecosystems. Waldram (1986, as cited in Castellano, 1999) explains that these observations are not conducted in the same way that a Western researcher would (repeated observations in a controlled environment), rather the observations were accumulated over time and are composed of a number of different vantage points. Waldram was able to identify and described in his work instances in which observations made by Aboriginal people in this manner were more valid conclusions than those based on traditional Western methodology.

The third, and final, component to Indigenous knowledge as outlined by Castellano (1999) is knowledge based on revelations. Dreams, visions and intuitions that are understood to be spiritual in origin, compose revealed knowledge. One such example is the tradition of vision quests. A vision quest was often the process through which youth made the transition to adulthood and sought guidance from the spiritual world through fasting and ceremony. Revealed knowledge is the component of Indigenous knowledge that is likely to be the most contested by those working from a Western paradigm. Western paradigms strive for the complete segregation of spirituality and scientific knowledge because they are perceived as fundamentally incompatible whereas Indigenous paradigms depict spirituality as an inextricable part of a holistic approach to the world. As a result knowledge gained from the spiritual part of the human experience is not to be ignored in favor of that which is based in the physical realm.

\section{Comparison of Western and Indigenous ways of knowing}

Indigenous knowledge and Indigenous ways of knowing have been subjugated in academic dialogue because Western ways of knowing are depicted as superior to Indigenous ways of knowing (Dumbrill \& Green, 2007; Wane, 2008). Brayboy and Castagno (2008) are among the many authors who argue that Indigenous ways of knowing are neither inferior nor superior to Western ways of knowing; rather they are a different perspective. Difference should not be devalued and, according to El-Hani and Bandeira (2008), Indigenous ways of knowing should be acknowledged as different rather than trying to justify their inclusion in the realm of Western science. As such, it is important to discuss the differences between Western ways of knowing and Indigenous ways of knowing.

There are many differences between Western and Indigenous ways of knowing; one of the most significant differences is that in the Western paradigm knowledge can be obtained and owned - in effect knowledge is a noun while the Indigenous conception focuses on knowing, a verb (Warner, 2006). This implies that Indigenous knowledge is not something which can be possessed by a single individual; it suggests that knowledge is shared with all of creation because all things are interconnected (Steinhauer, 2002).

Indigenous ways of knowing are described as relational because of the concept of interconnectedness and because Indigenous ways of knowing views things from a holistic perspective (Steinhauer, 2002). The relational nature of Indigenous ways of knowing is a stark contrast to Western ways of knowing which attempts to dissect and compartmentalize nature to understand it (Dumbrill \& Green, 2007; Warner, 2006). Indigenous ways of knowing do not discount analysis entirely; instead analysis must be balanced with synthesis. In addition, it is possible to draw a parallel with divide and conquer mentality used in Western ways of knowing to the colonization practices used when Europeans first colonized Canada (Schissel \& Wotherspoon, 2003; Wane, 2008); both are used to assert dominance without any regard for relationships. Indigenous ways of knowing require a respectful reciprocal relationship rather than an assertion of control (Steinhauer, 2002).

The Western paradigm attempts to remove relationships from the pursuit of knowledge in order to maintain objectivity (Dumbrill \& Green, 2007). In the Western paradigm, objectivity is imperative because it allows the researcher to find a single truth which is presumed to be globally applicable (Brayboy \& Castagno, 2008). This striving for objectivity is what precludes revealed knowledge from Western ways of knowing (Steinhauer, 2002). It is the principle of objectivity which, in Western ways of knowing, determines the validity of knowledge. In Indigenous ways of knowing objectivity is neither sought, nor considered desirable. There are those, such as Dr. Dawn Adrian Adams, who would argue that the notion of objectivity is not only false but that it conveys a false sense of control over the world (Pember, 2008). Indigenous knowledge, because of its roots in culture, varies substantially and suggests there are multiple realities rather than one objective reality. Indigenous ways of knowing suggest that you cannot remove something from its context and still have a useful understanding (Steinhauer, 2002). Castellano (1999) argues that to determine the usefulness of knowledge one has only to look at whether or not it enhances the capacity for people to live well. 
Western ways of knowing often exclude the spirit when attempting to understand people; there is ample research on the intellect, the physical body, and emotions - one only has to conduct a brief Google search to find thousands of web pages, books and scholarly publications on these topics. Yet the Western academy tends to remove the concept of spirit from scholarly work because spirit cannot be removed from the context of the individual and quantified or objectively studied (Dei, 2002). In Western ways of knowing if something cannot be studied empirically then it is devalued. Indigenous perspectives, however, value and honor the spirit in the understanding of people. This is again a reflection of a holistic worldview rather than the compartmentalization seen in Western ways of knowing.

There has been movement towards the integration of Indigenous knowledge and Indigenous ways of knowing in the research community, as evidenced by documents such the Ownership Control Access and Possession (OCAP) principles (Schnarch, 2004). OCAP has been described by Schnarch as "self-determination applied to research." Despite the advocacy for self-determination in education (Watt-Cloutier, 2000) the educational field lacks a unified approach to the integration of Indigenous principles.

\section{Indigenous knowledge and education}

Indigenous knowledge was passed down through an oral tradition for generations prior to contact with Europeans which interrupted the transmission of knowledge through use of colonial practices. Indigenous ways of knowing were used to teach children in an experiential manner (Schissel \& Wotherspoon, 2003). Children were taught through modeling and storytelling; education was conducted in a way that was integrated with daily life and emphasized relationships. Oftentimes elders and grandparents were responsible for the education of children while the parents were engaged in subsistence activities. Education, in traditional times, was preparation for life rather than simply a measure of academic achievement. Contact with Europeans introduced the Western academic system which had significant impact on the transmission and production of knowledge (Castellano, 1999).

The government of Canada promised to support the education of Indigenous peoples through various treaties (Stewart, 2006). This promise is in addition to the constitutional right of all Canadians to have equitable access to education. This education was promised as an optional addition to the daily lives of Indigenous peoples in Canada (Stewart, 2006) and was not supposed deter from traditional education in Indigenous communities (Cardinal \& Hildebrandt, 2000). This was a promise that was not kept.
Education in the Western system in Canada began as voluntary for Indigenous people but when Indigenous communities were not willing to give up their children the Canadian government adopted a coercive model as constructed in the Indian Act of 1876 (Dumbrill \& Green, 2007). The coercive model took the form of residential schools in the early 1920s (Schissel \&Wotherspoon, 2003). Aboriginal children were removed from their homes and families and taken to residential schools where they were isolated from their culture. Students were punished for speaking their own language or engaging in traditional activities, such as smudging (Roué, 2006). Residential schools were, in effect, a legislated form of cultural genocide (Schissel \& Wotherspoon, 2003). The last residential school was closed in 1996 (Assembly of First Nations, n.d.) yet the impact of residential school, and colonialism in general, is still prominent in the education of Aboriginal students today (Schissel \& Wotherspoon, 2003).

The detrimental impacts of oppressive education are seen not only in the lives of the students, but also in the lives of their families and the health of their communities (Schissel \& Wotherspoon, 2003). Many of the difficultiesfaced by Aboriginal communities today, which include mental health problems, physical health problems, and high rates of incarceration and morbidity, have all been linked to colonial history (Kirmayer, Simpson \& Cargo 2003; Wilson \& Rosenberg, 2002). There are also challenges specific to the field of Aboriginal education.

Aboriginal students in Canada have been noted as chronically underachieving (Schissel \& Wotherspoon, 2003; Stewart, 2006). Many Aboriginal students do not make it through the present academic structure to graduate. Stewart (2006) provides information based on a report by the Auditor general which indicates that while $65 \%$ of the general Canadian population has a minimum of high school education only $37 \%$ of the Indigenous population attains that minimum. Another focal point is the dropout rates. While the general Canadian population has a very low dropout rate prior to completion of grade nine $(3 \%)$ the dropout rate among Aboriginals is significantly higher (18\%). The dropout rates for students between the ages of 18 and 20 are $40 \%$ for Aboriginal students and $16 \%$ for the general population. Dropout rates are a reflection of the education gap. The education gap consists of the differences in levels of educational attainment, dropout rates, in school problems and socio-economic concerns (Schissel \&Wotherspoon, 2003). The widening education gap evidences that the present educational system is not serving Aboriginal students well (Watt-Cloutier, 2000).

There are those who would argue that colonial oppression is present in today's educational system though it takes on a more insidious form (Brayboy \& Castagno, 2008; Dumbrill 
\& Green, 2007; Schissel \& Wotherspoon, 2003). Oppression occurs whenever Indigenous ways of knowing are presented as less valuable, valid or legitimate than Western ways of knowing (Dumbrill \& Green, 2007; Wane, 2008). It is suggested that when Indigenous knowledge is presented as less than Western knowledge that this creates tensions and adjustment problems for students, which may contribute to high dropout rates (Schissel \& Wotherspoon, 2003). Moreover, Brayboy and Castagno (2008) state that much of the information presented in classrooms lacks relevance to the lives of Aboriginal students. Lee (2007) suggests that for Native students to gain meaning out of education that it must be relevant to their lives. Schissel and Wotherspoon (2003) also discuss how the boredom, stemming from the lack of relevant material, has been cited in much of the literature on dropout rates among Aboriginal students.

\section{Future of Indigenous Education}

Colonial history continues to impact the future of education for Aboriginal students; education was part of the oppressive history that has harmed Aboriginal peoples, nonetheless, it can potentially serve as part of the solution as well. As part of the solution, Indigenous knowledge needs to be meaningfully reintegrated into Aboriginal education (Watt-Cloutier, 2000). Indigenous knowledge should be included in the classroom to add relevance and pique the interest of Indigenous students (Lee, 2007). Community is valued in Indigenous ways of knowing and was traditionally part of education (Castellano, 1999); as such it is suggested that interaction with the community could be used to incorporate Indigenous knowledge into the educational system.

One suggestion for integration Indigenous knowledge and Indigenous ways of knowing into education is through the use of community based education (Lee, 2007; Schissel \& Wotherspoon, 2003). Community based models of education, such as the one used by Lee (2007), form an egalitarian partnership between schools and the communities they reside in. The communities are given opportunities for input on what their children are learning about and the children are able to gain experience through interactions with the community. Furthermore, the relationship with the community allows students to access the community's resources. Many community based models that have been used with Indigenous peoples have focussed on restoring Indigenous language (Lee, 2007; Schissel \& Wotherspoon, 2003) but there is nothing to indicate that this is the limit of the applicability of the community based model. In fact, the study conducted by Lee used community based education to explore math, science and environmental studies. Consequently, it is reasonable to suggest that community based models could be incorporated into the entire academic curriculum.

\section{Advantages of community based models of education}

There are specific advantages to using a community based model with Aboriginal populations. Community based models access community resources (Lee, 2007) and Aboriginal communities have a unique resource in the form of Elders. Community based models are designed to enhance contact between students and Elders (Schissel \& Wotherspoon, 2003). Schissel and Wotherspoon's study suggested that Aboriginal youth value Elders and their contributions to learning. Elders are often able to engage students in learning that they might not receive formally in the classroom. For example, Elders can teach students about the spiritual aspect of being or the story of Creation that is specific to their people. Elders are also able to pass on Indigenous knowledge to the students that is specific to the community.

Community based models are advantageous because they are based on the needs of the community. This enables students to focus on issues that are relevant to their lives (Lee,2007); when education is focussed on relevant issues it encourages students to engage more fully in learning (Schissel \& Wotherspoon, 2003). For Indigenous people, relevant issues are likely to include Indigenous knowledge and Indigenous ways of knowing (Bopp \& Bopp, 2001). However, this is not to suggest that the Western part of the curriculum in entirely removed because that would detrimentally impact the ability of students to interact in the dominant culture (Lee, 2007; Schissel \& Wotherspoon, 2003). The work by Bopp and Bopp (2001) indicates that the ability to be biculturally competent is important to Indigenous peoples; thus the goal is not to live solely in an Indigenous framework but to integrate Indigenous and Western frameworks to the benefit of the students.

A further benefit of community based models is that curriculum content is determined by the community rather than from an official who lacks a connection with the community (Lee, 2007). The implementation of curriculum by outsiders has historically caused a problem for Indigenous peoples. There is mistrust for the educational institution as a consequence of residential schools and there are those who would suggest that the government should not attempt to impose a solution to the problems in education that were created by the government (Schissel \& Wotherspoon, 2003). Lee Maracle (personal communication, October 23, 2008), in a panel discussion entitled "Towards Reconciliation: Residential Schools and the Role of Public Apology," suggested that non-Native individuals should give Native peoples the space they need to find the 
solution for themselves and should only step in when invited. This is also reflected in the document produced by the National Indian Brotherhood titled 'Indian Control of Indian Education' (Abele, Dittburner \& Graham, 2000). In this document the National Indian Brotherhood, now known as the Assembly of First Nations, suggests that regaining control of Indigenous education is essential for Indigenous peoples to achieve selfdetermination. Consequently a model which empowers Indigenous peoples to take control of their own education is highly valuable.

Multiple approaches to learning are used in community based approaches (Lee, 2007). The use of multiple approaches to learning make a community based model accessible to more students. Moreover, it allows students whose strengths are not accessed in the typical Western model of education to gain confidence in their abilities. Schissel and Wotherspoon (2003) suggest that Aboriginal students respond especially well to approaches that involve active experimentation. Active experimentation emphasises experiential learning rather than facts or abstract concepts. The article by Watt-Cloutier (2000) reinforces the concept that education should focus on skills rather than rote learning. Experiential learning is gained through extended and frequent field trips that allow students to explore their community in new ways or to access parts of the community that is normally unavailable to them. Allowing students to learn in their own community is a positive experience, as opposed to the negative experience when children were forcibly removed to residential schools. Participating in the community i enhances students' connections to their community, which is a step toward healing the wounds of the residential school system.

Community based models allow students to interact in a meaningful way with the communities and through this experience students develop interests in the community (Lee, 2007). By becoming interested in the community students are more likely to want to serve the community in their future endeavours. The development of these relationships is beneficial for both students and communities. Moreover, through this interaction students are able to experience interconnectedness and reciprocity in relationships. This experience is invaluable in teaching students about Indigenous knowledge and Indigenous ways of knowing.

\section{Challenges for community based models of education}

The community based model is not without its challenges. One of the most prominent obstacles to community based education is funding. Given that there are more field trips, interactions with the community and changes in curriculum it is presumed that community based education would be more costly than a regular curriculum. The potential for community based education to be more costly notwithstanding, Aboriginal education is consistently underfunded by the government and it is suggested that this contributes to the lower levels of educational attainment among Aboriginal students (Stewart, 2006). However, it is possible that rather than requiring more funds for Aboriginal education, that using a community based model would allow for the funds to be used more effectively and to better benefit the students. Alternatively, it is possible that the community may want to contribute to the funding if they are given control of the educational system.

Community control of curriculum has the potential to be extremely beneficial to students (Schissel and Wotherspoon, 2003) yet there is also the concern that if the changes to the curriculum are too extensive that students will not be able to achieve on standardized testing which may jeopardize their ability to pursue further educational opportunities. This concern may be addressed by ensuring the integration of Indigenous ways of knowing with Western ways of knowing rather than replacing one with the other. Western ways of knowing will remain important to students if they want to be able to engage productively with the dominant society (Lee, 2007). The challenge is finding an appropriate balance of the two paradigms.

Acquiring appropriate and skilled teachers who are able to facilitate the community based model is also challenging. Schissel and Wotherspoon (2003) suggest that for Aboriginal teachers to adequately provide for the number of Aboriginal students their numbers would have to increase three-fold. Although, the authors also point out that the available research regarding whether Aboriginal descent impacts success in teaching Aboriginal students is not conclusive. Research does, however, suggest that teachers must understand Aboriginal cultures and be sensitive to the learning needs of the students (Dumbrill \& Green, 2007)

The training of teachers is a challenge yet there are programs in place which train Aboriginal teachers and incorporate Indigenous knowledge and Indigenous ways of knowing into the training. Gardner (2000) discusses the Native Indian Teacher Education Program in place at the University of British Columbia. Another example is the Saskatchewan Urban Native Teacher Education Program that is based out of the Gabrielle Dumont Institute (Dorian \& Yang, 2000). The latter model has successfully used a community based approach for the education of teachers and the graduates of this program are highly regarded in their workplaces.

Community based education for Aboriginal peoples may also be challenged because it incorporates Indigenous ways of knowing which are different from Western ways of knowing. By incorporating Indigenous ways of knowing, community based 
education disputes the position of power in which Western ways of knowing have been placed (Castellano, 1999). The dominant paradigm is unlikely to shift overnight; the process will be slow and, at times, uncomfortable, yet Indigenous ways of knowing will hopefully be recognized as equal to Western ways of knowing (Castellano, 1999; Dumbrill \& Green, 2007; Schissel \& Wotherspoon, 2003).

Diversity among Indigenous peoples in Canada also poses a challenge. Although Indigenous knowledge and ways of knowing share commonalities there is significant differences between groups of Aboriginal peoples (Brayboy \& Castagno, 2008; Dumbrill \& Green, 2007; Schissel \& Wotherspoon, 2003). Consequently, it cannot be assumed that one model or template for community based education would work equally well for all Indigenous peoples in Canada. However, community based models are adaptable because they put a significant emphasis on the input of the community. Communities are able to use the components that are helpful and replace those that are not helpful with concepts that are helpful. The adaptability of community based education is implicit in the system because it is built around each unique community. Any concerns regarding standardization need to be looked at in context, as standardization is not the objective of community based education when learning about cultural practices; however, it is useful when considering developing curriculum that meets Canadian educational standards. Developing an integrated curriculum which balances Western and Indigenous worldviews will continue to be challenging though not impossible.

\section{Summary and Conclusion}

Indigenous ways of knowing, though different from Western ways of knowing, are a legitimate, valid and valuable way of looking at the world. Indigenous ways of knowing have persevered and adapted despite a history of oppression. Indigenous knowledge is diverse, holistic, personal and part of a lived experience.

The integration of Indigenous knowledge into education is essential for the progress of Aboriginal education and the movement away from colonial practices A community based model of education is suggested as the way by which Indigenous knowledge and ways of knowing can be integrated into the educational system. The community based model has both advantages and challenges, and it has been successful in both high school (Lee, 2007) and post-secondary endeavours (Dorian \& Yang, 2000). The challenge now is to implement this model on a more widespread basis -- to have community based education become the norm rather than the exception. Although the progress towards equality in education is slow, progress is being made nonetheless.
It is better to take many small steps in the right direction than to a great leap forward only to stumble backward.

\section{Chinese proverb}

\section{References}

Abele, F., Dittburner, C. \& Graham, K. A. (2000). Policy discussion about Aboriginal education. In M. B. Castellano, L. Davis \& L. Lahache (Eds.) Aboriginal Education: Fulfilling the Promise (pp. 3-24). Vancouver, BC: University of British Columbia Press.

Assembly of First Nations. (n.d.). History of Indian residential schools. Retrieved December 1, 2008 from http://www.afn.ca/residentialschools/history. html.

Battiste, M. (1998). Enabling the autumn seed: Toward a decolonized approach to Aboriginal knowledge, language, education. Canadian Journal of Native Education, 22 (1), 16-27.

Bopp, M \& Bopp, J. (2001). Recreating the world: A practical guide to building sustainable communities. Lethbridge, AB: Four Worlds Press.

Brayboy, B. M. J. \& Castagno, A. E. (2008). How might Native science inform "informal science learning"? Cultural Studies of Science Education, 3, 731-750.

Cardinal, H., \& Hildebrandt, W. (2000). Treaty Elders of Saskatchewan. Calgary, AB: University of Calgary Press.

Castellano, M. B. (1999). Updating traditions of Aboriginal knowledge. In B. L. Hall, G. J. S. Dei, \& D. G. Rosenberg (Eds.) Indigenous Knowledges in Global Contexts (pp. 21-36). Toronto, ON: University of Toronto Press.

Dei, G. S. (2002). Learning Culture, Spirituality and Local Knowledge: Implications for African Schooling. International Review of Education, 48 (5), 335-360.

Dorian, J. \& Yang, K. R. (2000). Métis post-secondary education: A case study of Gabriel Dumont Institute. In M. B. Castellano, L. Davis \& L. Lahache (Eds.) Aboriginal Education: Fulfilling the Promise (pp. 3-24). Vancouver, BC: University of British Columbia Press.

Dumbrill, G. C. \& Green, J. R. (2007). Including Indigenous knowledge in webbased learning.

El-Hani, C. B \& Bandeira, F. P. (2008). Valuing indigenous knowledge: To call it "science" will not help. Cultural Studies of Science Education, 3 (3), 751-779.

Gardner, E. (2000). First Nations house of learning: A continuity of transformation. In M. B. Castellano, L. Davis \& L. Lahache (Eds.) Aboriginal Education: Fulfilling the Promise (pp. 190-207). Vancouver, BC: University of British Columbia Press.

International Working Group for Indigenous Affairs. (1996). Indigenous World Report. Copenhagen: Author.

Kirmayer, L. J., Simpson, C., \& Cargo, M. (2003). Healing traditions: culture, community and mental health promotion with Canadian Aboriginal peoples. Australasian Psychiatry, 11 (Suppl. 1), 15-23.

Kundston, P. \& Suzuki, D. (1992). Wisdom of the Elders. Toronto, ON: Allen \& Unwin. Journal of Technology in Human Services, 25 (1), 103-117.

Lee, T. S. (2007). Connecting academics, Indigenous knowledge and commitment to community High school students' perceptions of a community-based education. Canadian Journal of Native Education, 20 (2) $196-215$ 
First Peoples Child \& Family Review, Volume 5, Number 2, 2010

Milligan, S. \& Bougie, E. (2009). First Nations women and postsecondary education in Canada: Snapshots from the census. Retrieved September 1, 2010 from http://www.statcan.gc.ca/pub/81-004-x/2009004/article/11017-eng. htm.

O’Neill, J. \& Dalrymple, T. (2008 June 12). Natives applaud residential school apology. Calgary Herald, pp. Al and A5.

Pember, M. A. (2008). Diversifying Pedagogy. Diverse Issues in Higher Education, $25(5), 18-20$.

Restoule, B. (1997). Providing services to Aboriginal clients. Guidance Counselling, 12 (2), 13-17.

Robertson, L. H. (2006). The residential school experience: Syndrome or historic trauma. Pimatisiwin: A Journal of Aboriginal and Indigenous Community Health, 4 (1), 1-28.

Roué, M. (2006). Healing the wounds of school by returning to the land: Cree elders come to the rescue of a lost generation. International Social Science Journal, 58 (187), 15-24.

Schissel, B. \& Wotherspoon, T. (2003). The Legacy of School for Aboriginal People: Education, Oppression and Emancipation. Don Mills, ON: Oxford University Press.

Schnarch, B. (2004). Ownership, control, access and possession (OCAP) or self-determination applied to research: A critical analysis of contemporary First Nations research and some options for First Nations communities. Journal of Aboriginal Health, 80-95.

Steinhauer, E. (2002). Thoughts on an Indigenous research methodology. Canadian Journal of Native Education, 26 (2), 69-81.

Stewart, S. C. (2006). First Nations education: Financial accountability and educational attainment. Canadian Journal of Education, 29 (4), 998-1018.

Wane, N. N. (2008). Mapping the field of Indigenous knowledges in anticolonial discourse: a transformative journey in education. Race, Ethnicity, and Education, 11 (2), 183-197.

Warner, L. S. (2006). Native ways of knowing: Let me count the ways. Canadian Journal of Native Education, 29 (2), 149-164.

Watt-Cloutier, S. (2000). Honouring our past, creating our future: Education in Northern and remote communities. In M. B. Castellano, L. Davis \& L. Lahache (Eds.) Aboriginal Education: Fulfilling the Promise (pp. 114-128). Vancouver, BC: University of British Columbia Press.

Wilson, K. \& Rosenberg, M. W. (2002). Exploring the determinants of health for First Nations peoples in Canada: can existing frameworks accommodate traditional activities? Social Sciences \& Medicine, 55, 2017-2031. 